\title{
Hospital de animais silvestres: categoria ausente na estrutura de proteção à fauna brasileira
}

Dentre os estabelecimentos aptos a manter animais silvestres em cativeiro, o ordenamento jurídico brasileiro não prevê a categoria hospital. Partindo dessa constatação, o presente artigo recorre à pesquisa de campo em um hospital universitário veterinário (HUV) especializado no atendimento a animais silvestres, com o objetivo de identificar características distintivas deste tipo de instituição em face das categorias legalmente previstas. Pauta-se por pesquisa qualitativa empregando os métodos de observação participante e entrevistas semiestruturadas. Ao desvelar as especificidades da citada categoria e indicar as utopias que animam sua concretização no mundo social, o trabalho conclui que a negação de seu reconhecimento pelas autoridades ambientais reflete a valorização de contrastantes significados atribuídos à noção de proteção à fauna. Conclui, também, que tal lacuna afeta o modo como os estagiários e médicos veterinários residentes do HUV constroem suas percepções quanto aos objetivos que devem perseguir, traindo as utopias fundantes de seu projeto e dificultando a efetividade da ação conservacionista.

Palavras-chave: Conservação; Eutanásia; Hospitalização; Sociobiodiversidade; Urbano amazônico.

\section{Hospital of wild animals: an absent category in the Brazilian fauna protection structure}

\begin{abstract}
Among the institutions allowed to keep wild animals in captivity, the Brazilian legal system provides no space for the hospital category. Based on such fact, this article resorts to field research in a university veterinary hospital (UVH) specialized in the care of wild animals, aiming to identify distinctive characteristics of this type of institution in relation to the legally recognized categories. Research is guided by qualitative methods, using participant observation and semi-structured interviews. By revealing the particularities of this category and indicating the utopias that animate its existence in the social world, the paper concludes that the denial of its recognition by the environmental authorities reflects the alignment to contrasting conceptions on the notion of fauna protection. It also concludes that such denial affects the way UVH resident trainees and veterinarians construct their perceptions of the objectives to be pursued, betraying the very founding utopias of their project and hampering the effectiveness of conservation action.
\end{abstract}

Keywords: Conservation; Euthanasia; Hospitalization; Sociobiodiversity; Urban Amazon.

Topic: Conservação da Biodiversidade

Reviewed anonymously in the process of blind peer.
Received: 02/12/2018

Approved: 26/01/2019
Robertho Marconi Santos Ruas (id

Universidade Federal Rural da Amazônia, Brasil

http://lattes.cnpq.br/2689167905355767

http://orcid.org/0000-0001-9858-5577

marconeruas@yahoo.com.br

\section{Diego Corrêa Furtado (D}

Universidade Federal do Oeste do Pará, Brasil

http://lattes.cnpq.br/6665682528798800

http://orcid.org/0000-0001-6007-0471

dkhasinau@gmail.com

Cinthia Távora de Albuquerque Lopes

Universidade Federal do Pará, Brasil

http://lattes.cnpq.br/0196582874216634

cinthiatal@gmail.com

\author{
Gutemberg Armando Diniz Guerra (it) \\ Universidade Federal do Pará, Brasil \\ http://lattes.cnpq.br/4262726973211880 \\ http://orcid.org/0000-0002-8122-1141 \\ gguerra@ufpa.br \\ Luly Rodrigues da Cunha Fischer (iD) \\ Universidade Federal do Pará, Brasil \\ http://lattes.cnpq.br/5038078976448551 \\ http://orcid.org/0000-0002-1662-8703 \\ lulyfischer@yahoo.com \\ Sheyla Farhayldes Souza Domingues itio \\ Universidade Federal do Pará, Brasil \\ http://lattes.cnpq.br/2794753357251149 \\ http://orcid.org/0000-0002-6017-7647 \\ shfarha@gmail.com
}

Referencing this:

RUAS, R. M. S.; FURTADO, D. C.; LOPES, C. T. A.; GUERRA, G. A. D.; FISCHER, L. R. C.; DOMINGUES, S. F. S.. Conservation; Euthanasia; Hospitalization; Sociobiodiversity; Urban Amazon.. Revista Ibero Americana de Ciências Ambientais, v.10, n.1, p.46-63, 2019. DOI: http://doi.org/10.6008/CBPC2179-6858.2019.001.0005

DOI: 10.6008/CBPC2179-6858.2019.001.0005 


\section{INTRODUÇÃO}

O debate acadêmico remetido à temática da conservação do meio ambiente tem progressivamente passado a acentuar a importância da participação das populações rurais, extrativistas e indígenas na gestão dos recursos naturais (FÜRSTENAU-TOGASHI et al., 2012). Ultrapassando visões de uma natureza exótica, distante e intocada (DIEGUES, 2000), passam a se erigir, no meio acadêmico, ao contrário, utopias de cunho 'socioconservacionista', que conjecturam configurações de idealizada harmonia entre sociedade e ambiente (ADAMS, 2000).

Ao passo em que as projetadas utopias de um mundo ideal inspiram iniciativas e mobilizações no dito 'mundo real', elas entram em inevitável conflito com as já institucionalizadas e vigentes configurações de estruturação da realidade social. As leis e as ações governamentais relativas à proteção do meio ambiente, afinal, continuam apartadas do mencionado debate, pautando-se preponderantemente por instrumentos de coerção que desconsideram - ou mesmo criminalizam - as especificidades dos modos de vida dos grupos ditos tradicionais (ARRUDA, 1999).

A disparidade entre alternativos projetos que concorrem para ordenar as relações entre sociedade e natureza não se restringe, porém, ao aspecto simbólico, do embate de ideias. Como se pretende demonstrar, ela encontra expressão nas cadeias de ações e interações atualizadas por atores sociais específicos, cuja atuação em papéis hierarquizados concretiza tendências de reprodução ou ruptura de um determinado status quo socioambiental.

Partindo desse raciocínio geral, o artigo se dirige em particular ao processo de embate entre divergentes visões relativas à participação do Poder Público na proteção da fauna silvestre. Busca evidenciar como, por detrás do que parece uma mera disputa nomenclatural, reside uma disputa mais complexa, relativa ao reconhecimento da especificidade de uma visão que resiste a se deixar domesticar pela visão predominante acerca do tema.

Em termos diretos, pretende-se refletir sobre a pertinência da inclusão da categoria de 'hospital de animais silvestres' no rol de estabelecimentos participantes da estrutura de proteção à fauna reconhecida pelo Estado brasileiro. Contrapondo-se à ideia de que a aludida categoria é redundante em relação àquelas já previstas no ordenamento jurídico, o artigo argumenta que o conceito 'hospital' se diferencia por se remeter a objetivos e utopias particulares, incompatíveis com as categorias existentes. E, se esvaziados os objetivos e utopias subjacentes ao conceito de hospital, defende o texto, a própria capacidade dessas instituições de prestar efetiva contribuição à proteção da fauna silvestre seria severamente comprometida.

\section{REVISÃO TEÓRICA}

\section{Modelos de funcionamento da máquina estatal}

O artigo, como já postulado, pretende analisar aspectos da trajetória do HUV em busca de reconhecimento, pelos órgãos públicos do setor de meio ambiente, da categoria hospital como diferenciada modalidade institucional de proteção à fauna. Conquanto os pormenores da caracterização do HUV devam 
ser elucidados no curso do texto, é pré-condição para tal, desde já, esclarecer o sentido com que se empregam termos, ao longo do trabalho, tais quais 'máquina estatal', 'Poder Público', 'administração pública', 'agentes/órgãos do governo'. É, pois, a esfera das instituições formais (BERGER et al., 1966; TÖNNIES, 1973) o lócus de articulações e embates em cujo âmbito o HUV negocia o reconhecimento de sua legitimidade social.

Precedendo as variadas utopias que sucessivamente irrompem para anunciar renovados ideais de estruturação de relações sociedade \& natureza, existe um aparelho estatal estável, comprometido a concretizar tais relações dentro de parâmetros próprios, fixados em leis e demais espécies normativas. 0 conhecimento de tal dinâmica é imprescindível para que se possa discutir em que medida as novas ideias forjadas têm ou não condições de prosperar em face da ortodoxia.

A administração pública - tipicamente o Poder Executivo - pode ser analisada como aparelho ou máquina estatal: conjunto de órgãos e entidades comprometidos com a gestão do patrimônio público e a prestação de serviços públicos (SARAI, 2011). A segmentação da máquina pública em órgãos especializados permite a execução compartimentalizada de suas diferentes funções. Esses órgãos e entidades têm patrimônio (prédios, veículos, equipamentos) e contratam funcionários (servidores públicos) para realizar suas missões institucionais, que refletem os ditames da lei e, em última análise, buscam satisfazer o interesse público, fator de legitimidade do ordenamento jurídico (JUSTEN FILHO, 2016). É, aliás, devido ao princípio da prevalência do interesse público sobre o privado (SCHIER, 2004), que se outorga, aos agentes da máquina estatal, a prerrogativa de impor coercitivamente os comandos da lei (JUSTEN FILHO, 2016). Embora preliminar, esta definição retém o essencial da ideia.

O modelo que até hoje domina a administração pública brasileira foi formatado na década de 1930, durante o governo de Getúlio Vargas, conforme discorre Costa (2008). Visando cessar a interpenetração entre interesse público e interesses particulares dos governantes, traço característico do modelo de administração patrimonialista então em voga (CASTRO, 2015; HOLANDA, 1936), Vargas instituiu a administração burocrática (COSTA, 2008). A burocracia tem, dentre suas bases, a impessoalidade e a legalidade (BAUMAN et al., 2010). Assim, a administração não deveria se pautar por interesses pessoais de um ou outro indivíduo, mas pelo interesse de toda a sociedade, o que só se poderia alcançar pelo estrito respeito aos critérios e padrões previstos nas leis.

Embora tenha atenuado os traços de patrimonialismo do aparelho estatal, o modelo de administração burocrática foi criticado por seu exagerado formalismo, que impunha rigidez aos procedimentos administrativos e decisórios. A legalidade, que pretendia dotar de objetividade o trato da coisa pública, se transmutou em legalismo, pois o valor máximo perseguido passou a ser o estrito cumprimento das leis, não a satisfação das necessidades da sociedade. Enquanto permitiu relativa moralização da máquina pública, este modelo administrativo ficou marcado pela ineficiência e pela pouca efetividade na prestação de serviços públicos (MEDEIROS, 2006).

O modelo burocrático, jamais tendo suplantado plenamente o patrimonialismo precedente, teve ainda que ceder terreno, a partir de 1967, já nos dias de ditadura militar, a um terceiro modelo administrativo: 
o gerencial. O modelo gerencial se pauta pela flexibilidade e maior liberdade dos gestores públicos e foi utilizado basicamente nos setores de atuação governamental junto ao mercado e na exploração de atividades econômicas (p. ex., setor de petróleo). Assim, o modelo gerencial se restringiu à administração indireta, particularmente às empresas públicas e sociedades de economia mista (p. ex., Banco do Brasil, Caixa Econômica Federal, Petrobras), restando predominante, nos demais setores, o modelo burocrático (BRESSERPEREIRA, 1996).

O funcionamento do aparelho do Estado se mantém ainda hoje leal ao universo de critérios do modelo burocrático, suas correspondentes categorias classificatórias e padrões fixados nas leis. Embora propicie maior objetividade à atuação dos agentes do Estado e às relações entre Estado e indivíduo, o grande dilema intrínseco a este modelo talvez nem seja sua tendência à ineficiência, mas a irreconciliável contradição, dele decorrente, entre a sociedade ideal, uma sociedade em parte ultrapassada, cujos parâmetros permanecem petrificados nas leis, e a sociedade real, tal qual ela é, em incessante movimento e transformação (ABRUCIO, 1997).

Reportando sua atuação a categorias jurídicas datadas, cuja reformulação não acompanha em ritmo satisfatório as transformações da sociedade, a máquina estatal se mantém voltada mais para si própria que para a sociedade que pretende organizar. Impõe categorias classificatórias necessárias, sim, à pacificação das relações jurídicas, porém simplificadoras das especificidades das situações sociais classificadas.

Priorizando seu universo conceitual próprio em detrimento da realidade social, o modelo burocrático cria, para esta, embaraços, pois obriga que as pessoas e as situações concretas se enquadrem em categorias previamente fixadas, mesmo quando isso implica a negação de amplos aspectos de suas existências (RUAS et al., 2017). Sob esse prisma, o modelo burocrático seria uma fábrica de conflitos. Trata-se, porém, de uma imagem propositalmente exagerada para acentuar específicos traços distintivos desse modelo administrativo que importam à temática em foco.

\section{Adendo: a especificidade dos órgãos universitários}

Os órgãos ambientais - com missão institucional claramente definida - têm sua atuação rigidamente pautada pela consecução dos objetivos expressos nas leis. As universidades e seus respectivos órgãos, por sua vez, embora igualmente submetidos ao império da lei, gozam de relativa liberdade para inovar. Desde que se mantenham circunscritos ao tripé ensino-pesquisa-extensão, os órgãos universitários, observados os procedimentos burocráticos aplicáveis, possuem legitimidade para propor e desenvolver renovadas linhas de atuação e para reformular e redirecionar os parâmetros de sua estruturação didático-científica. Como apontado por Durham (2006), este é o mais marcante aspecto de diferenciação das universidades públicas brasileiras em face das demais instituições componentes da máquina estatal.

É em razão desse caráter relativamente autônomo das universidades, e também devido ao pouco tempo de funcionamento do HUV, que a correta caracterização de sua dinâmica institucional depende de que se reconheçam os elementos significativos de seu processo de estabelecimento. Apenas uma análise do 
processo de constituição do HUV permitiria, pois, elucidar de forma contextualizada a erupção e reprodução de tensões e conflitos entre este órgão universitário e os órgãos ambientais atuantes na mesma circunscrição.

\section{METODOLOGIA}

O presente trabalho decorre de pesquisa realizada no âmbito de um Hospital Universitário Veterinário (HUV) localizado em área urbana da Amazônia brasileira, no estado do Pará. A instituição atua desde 2013 e se apresenta como centro de especializado atendimento a animais silvestres. Conforme compromisso de sigilo previsto no protocolo de pesquisa aprovado por Comitê de Ética em Pesquisa com Seres Humanos, a instituição não será identificada. A análise dos aspectos éticos da pesquisa pelo indicado tipo de comitê decorre, aliás, do fato de que, embora tratando de tema correlato à saúde animal, a investigação enfocou especificamente os atores humanos envolvidos na prestação de serviços nessa área de atuação profissional.

A pesquisa se constitui como estudo de caso, pois se socorre da análise de um significativo caso empírico - o contexto institucional do HUV - para propor reflexões generalizantes acerca das categorias de análise focalizadas. Adota-se perspectiva interdisciplinar, uma vez que, tentando compreender o processo de constituição do hospital veterinário como espaço de intervenção sobre processos socioambientais, o estudo dialoga com áreas tão diversas quanto as Ciências Sociais, o Direito, a Gestão Pública e a Biologia da Conservação.

Como método, emprega-se observação participante, que, segundo Sáez (2013), "mais do que uma técnica, é um ambiente", ambiente dentro do qual a prolongada convivência com os sujeitos da pesquisa permite desvelar os significados de suas ações concretas, de outro modo ocultos pela naturalização do cotidiano. A permanência da equipe de pesquisa no HUV se estendeu de 2015 até 2017, oportunizando o testemunho de variadas situações de intercurso envolvendo a equipe técnica da instituição (formada por médicos veterinários do quadro funcional efetivo, veterinários residentes, docentes, pesquisadores e estagiários) e sua clientela (inclusive aquela formada por agentes de outras instituições, como os órgãos ambientais).

A compreensão dos aspectos correlatos à problemática levantada também se beneficiou sobremaneira da realização de entrevistas com alguns membros da equipe técnica do HUV, observados os procedimentos éticos de sigilo e a prévia assinatura de Termo de Consentimento Livre e Esclarecido (TCLE). O contato com estes interlocutores permitiu não apenas conhecer suas percepções subjetivas correlatas à temática em estudo, mas também conhecer suas memórias concernentes a fatos ocorridos no HUV nos anos que precederam a pesquisa de campo (de 2013 e 2014).

É necessário pontuar que, embora alguns membros da equipe técnica do HUV tenham permanecido atrelados à instituição durante toda a duração da pesquisa, sua composição é bastante variável. Isso decorre do fato de que um HUV, ressalvados os cargos ocupados por servidores públicos de carreira, se caracteriza por disponibilizar vagas para vinculação temporária de estudantes, como estagiários de cursos de graduação, e de veterinários ligados a programas de residência médica. 
Ao invés de figurar como obstáculo à caracterização dos fenômenos estudados, a variabilidade de composição do HUV favoreceu a análise pretendida. Mediante colaboração dos servidores de carreira, portadores de vinculação fixa ao HUV, foi possível reconhecer, nas sucessivas 'gerações' de colaboradores temporários, distintas fases de desenvolvimento da instituição. Isto permitiu identificar marcos significativos do histórico de relações travadas pelo HUV em busca de seu reconhecimento institucional - e do reconhecimento de sua particular perspectiva de conservação. A representação esquemática apresentada na Figura 1 resume a dinâmica de intercurso social estabelecida no âmbito do HUV durante a pesquisa de campo.

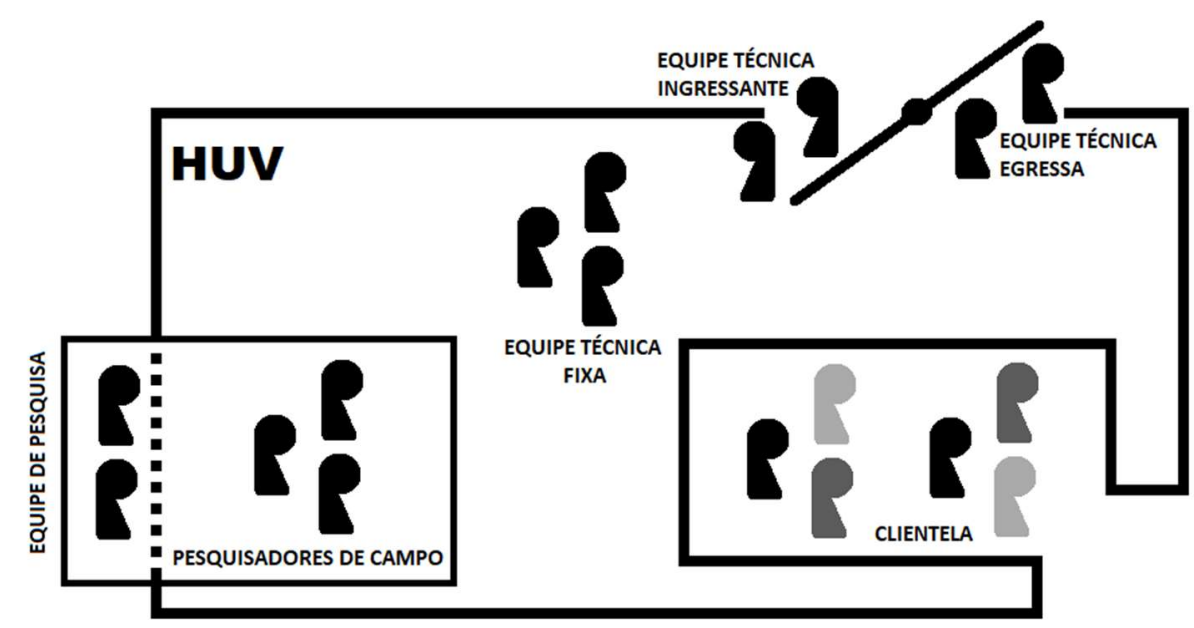

Figura 1: Tipologia dos atores sociais em intercurso no HUV. Legenda: no canto superior direito, destaque para a composição dinâmica da equipe técnica da instituição; no canto inferior direito, destaque para a constituição heterogênea da clientela. A representação da clientela em cor sólida preta e em tons de cinza reflete a coexistência de atores com motivações bem definidas (p. ex., órgãos ambientais) e atores com motivações particulares não atreladas a funções institucionais.

\section{RESULTADOS E DISCUSSÃO}

\section{O advento do HUV: voluntários e inventores}

No ano de 2013, entrou em funcionamento o HUV, inspirado por utopias conservacionistas, compartilhadas por seus fundadores, quanto à temática dos animais silvestres. Tratava-se de um grupo de professores universitários, pós-graduandos e graduandos circunscritos a uma área técnica, a medicina veterinária, que, embora sensibilizados pela problemática da proteção à fauna, não possuía afinidade com a complexa discussão interdisciplinar subjacente ao tema da conservação ambiental.

O funcionamento do HUV foi inicialmente viabilizado pelo trabalho voluntário do grupo de pessoas acima referido. Porém, os vínculos de trabalho da equipe técnica da instituição foram paulatinamente formalizados. Designou-se um médico veterinário como responsável técnico pelo HUV e implantaram-se mecanismos de recrutamento contínuo de profissionais por meio de programa de residência médicoveterinária e de recepção de estagiários de graduação. A fase do voluntariado, desse modo, findou.

Os traços de horizontalidade, voluntariedade e informalidade típicos dos inaugurais vínculos atualizados no HUV foram progressivamente substituídos por hierarquizadas relações de trabalho. Alguns dos interlocutores da pesquisa relatam que a inicial ausência de uma coordenação centralizada tornava comuns 
as falhas de comunicação entre os colaboradores do HUV, levando a conflitos internos. Além disso, a falta de profissional com função supervisora comprometia a uniformidade das intervenções médicas, prejudicando a eficácia dos atendimentos.

Ao longo do processo de institucionalização e hierarquização do HUV, as rotinas de trabalho e procedimentos de documentação também se modificaram. Inicialmente, utilizavam-se modelos de fichas e prontuários próprios para registro de atendimentos a animais domésticos (p. ex., cães, gatos, equinos, bovinos), pois este era o material mais fartamente disponível. A prática obrigou, porém, a implementação de sucessivas adaptações a esses instrumentos, a fim de compatibilizá-los às especificidades do trabalho com animais silvestres. A anamnese (ato em que um veterinário inquire um condutor acerca das causas e circunstâncias da condução de um animal ao HUV) de um paciente da fauna silvestre, por exemplo, deve esclarecer seu grau de domesticação, preocupação inexistente no caso dos animais domésticos.

Outro aspecto a apresentar considerável variação no decurso temporal foi o arcabouço de conhecimentos técnicos da equipe acerca da assistência veterinária a animais silvestres. A primeira geração de técnicos vinculados ao HUV (os voluntários) se queixava de que o trabalho com esse tipo de animais gerava uma maior demanda de esforços em relação aos animais domésticos. Seus conhecimentos da biologia, nutrição e comportamento dos animais silvestres se respaldavam, pois, em referencial técnico relativamente escasso, se comparado àquele disponível acerca de animais domésticos.

Havia, nos primórdios do funcionamento do HUV, um sentido de novidade e desafio a cada atendimento, pois muitos conhecimentos demandados para a realização das intervenções propostas não estavam disponíveis e precisavam ser estabelecidos ad hoc, conforme os casos concretos se apresentavam. Assim, apenas a passagem do tempo e o consequente acúmulo de experiências permitiram a elaboração do referencial antes indisponível, o que se refletiu no aumento da eficácia dos atendimentos prestados e na melhora da sobrevida dos pacientes.

\section{A busca pela conformidade}

Enquanto ainda estruturava suas instalações e equipe, o HUV começou a ser procurado por pessoas de distintos segmentos sociais - desde instituições públicas, como Corpo de Bombeiros e órgãos de meio ambiente, até moradores locais -, buscando atendimento a animais silvestres. Ao ouvirem falar da abertura de uma instituição deste tipo na cidade, com profissionais especificamente dedicados ao trato da fauna silvestre, os citados condutores ali reconheceram um potencial lócus de acolhimento para uma demanda até então reprimida de pacientes.

Apesar de o HUV não ter, à época, regularizado sua situação como estabelecimento de reabilitação da fauna silvestre junto aos órgãos ambientais, seus técnicos não puderam se furtar da obrigação de atender os pacientes levados à sua presença. Determina, pois, seu próprio conselho de fiscalização profissional, o Conselho Federal de Medicina Veterinária (CFMV), por meio da Resolução CFMV 829/2006, que "Os animais silvestres/selvagens devem receber assistência médica veterinária independentemente de sua origem" (Artigo 1ㅇ) (CFMV, 2006). 
A equipe do HUV reconhecia, porém, desde então, que a prerrogativa conferida pelo CFMV a seus registrados se configurava como instrumento precário de atuação, pois sequer era mencionada na legislação brasileira de meio ambiente (domínio que cuida da tutela jurídica da fauna). Buscou-se, pois, a regularização do HUV em face dos órgãos ambientais, para que sua equipe se tornasse apta a realizar suas intervenções conforme padrões mais explícitos, para além do vago termo 'assistência'.

A interlocução de representantes do HUV com agentes dos órgãos ambientais permitiu descobrir que o ordenamento jurídico não reconhece a categoria 'hospital de animais silvestres' dentre aquelas habilitadas a realizar o manejo da fauna em cativeiro. Ao estabelecer taxativamente as categorias de uso e manejo da fauna silvestre em cativeiro, a Instrução Normativa no 07 de 2015 do Ibama (Instituto Brasileiro e Meio Ambiente e dos Recursos Naturais Renováveis) não deixa margem para proposição de novas categorias, reservando apenas duas ao objetivo de reabilitação de espécimes da fauna silvestre:

Art. 3으 Ficam estabelecidas exclusivamente as seguintes categorias (...):

I - centro de triagem de fauna silvestre: empreendimento (...) com finalidade de receber, identificar, marcar, triar, avaliar, recuperar, reabilitar e destinar fauna silvestre proveniente da ação da fiscalização, resgates ou entrega voluntária de particulares (...);

II - centro de reabilitação da fauna silvestre nativa: empreendimento (...) com finalidade de receber, identificar, marcar, triar, avaliar, recuperar, reabilitar e destinar espécimes da fauna silvestre nativa para fins de reintrodução no ambiente natural (...). (IBAMA, 2015).

Posterior atualização da normativa citada, a Resolução CONAMA no 489 (CONAMA, 2018, art. 4ํ) reuniu em uma mesma categoria as duas categorias indicadas supra e passou a albergar a hipótese de que outras categorias de manejo de fauna silvestre em cativeiro possam ser definidas pelo órgão ambiental competente. Apesar disso, novamente manteve silêncio a respeito da pleiteada categoria de hospital de animais silvestres.

Desse modo, respaldados por um instrumento precário de atuação e pleiteantes de uma forma imprevista de reconhecimento, os técnicos do HUV passaram a esboçar uma incerteza acerca da legalidade de sua atuação. Pouco conhecendo sobre o conjunto da legislação ambiental, alguns imaginavam caminhar sobre um terreno de ambiguidade, sujeitando-se a incompreensões e ao risco de acusações contra suas condutas.

Enfrentando dificuldades para efetivar seu enquadramento e ser reconhecido perante os órgãos ambientais, o HUV foi instado a adotar procedimentos indicativos de compromisso com a legislação ambiental vigente. A rotina de recepção de portadores de animais silvestres passou a obedecer a um rito peculiar e de obrigatória observância - também imposto pela supracitada resolução 829/2006 do CFMV. Aos técnicos responsáveis pelo atendimento ao público, incumbiu-se o dever de prestar, aos condutores dos animais, informações sobre as disposições legais relativas à posse não autorizada de fauna silvestre, e também de anotar seus dados de identificação - nome completo e números de Registro Geral (RG) e de inscrição no Cadastro de Pessoa Física (CPF) - e localização - endereço e número de contato telefônico. 


\section{A rigidez normativa no olimpo da sociobiodiversidade}

Embora constituída por procedimentos coreografados e impessoais, a citada dinâmica de esclarecimento e registro passou a ser interpretada, por determinados segmentos de portadores de animais - sobretudo aqueles não vinculados a nenhuma instituição formal -, como estratégia de intimidação. Tratarse-ia de um rito de implícita acusação ou insinuação de qualidades criminosas dos atos desses portadores.

Na visão de parcela da equipe do HUV, não há constrangimento nenhum nessa forma de abordagem, qualificando-se os procedimentos adotados como simples 'orientação. Outra parcela dos técnicos diz reconhecer, ao contrário, que a menção às normas ambientais durante a recepção aos portadores dá, a este momento, um tom acusatório que assusta os condutores individuais (não institucionais) e os afugenta. Tal quebra de confiança entre médico e cliente (portador), por fim, inviabilizaria a continuidade do atendimento ao paciente, o animal silvestre. Inviabilizaria não apenas o retorno do animal ao HUV, para prosseguimento do tratamento, como também a localização do portador - quem, afinal, vendo-se perante uma situação de ameaça, forneceria dados verdadeiros e completos de identificação e contato?

Desse modo, os técnicos do HUV se veem na difícil situação de ter que optar entre a necessidade de adequação ao sistema de gestão ambiental pública tal qual existe - enrijecido em torno do dualismo legal x ilegal -, e a obrigação profissional de restituir a saúde de animais oriundos de circunstâncias as mais diversas. No cotidiano do hospital, aliás, nunca faltaram situações dúbias, em que os técnicos identificassem lacunas e contradições nas declarações feitas pelos portadores de animais, e isto instaura um dilema: os veterinários devem atuar como fiscais de meio ambiente, ou devem se restringir ao papel de médicos e priorizar a reabilitação dos pacientes?.

A dúvida é especialmente legítima se for considerado que, por mais suspeitas que soem as histórias narradas por alguns clientes do HUV para justificar a posse de um animal silvestre, em nenhum momento pareceu plausível a hipótese de que se tratassem de casos de tráfico de fauna. Como argumentam, pois, Licarião et al. (2013) e Pereira et al. (2005), sequer haveria razões para crer que traficantes de animais se interessariam em procurar instâncias formais para reabilitar espécimes machucados; prática, aliás, incompatível com o modus operandi de seu negócio.

Em assim sendo, o que, afinal, se espera que a equipe do HUV denuncie aos órgãos ambientais? As imemoriais relações homem $x$ fauna que fazem da Amazônia uma das mais ricas regiões de sociobiodiversidade? Nem mesmo a localização urbana do HUV invalida o argumento, pois os estudos atestam a reprodução deste intercurso até nas grandes e médias cidades amazônicas (BAÍA JÚNIOR et al., 2010; BARROS et al., 2014; MORSELLO et al., 2015; PARRY et al., 2014; REBÊLO et al., 2000; RIBEIRO et al., 2007; SILVA, 2008; VLIET et al., 2015).

O dilema antes mencionado exige, em última instância, que o veterinário decida entre garantir a efetividade de sua intervenção médica ou colaborar ativamente na responsabilização de um suposto infrator da legislação ambiental. Compatibilizar os dois objetivos parece, na prática, tarefa desafiadora, senão irrealizável. Apesar disso tudo, o HUV tem preferido manter os procedimentos de documentação dos 
pacientes e de orientação dos respectivos portadores, conforme padrões estabelecidos pelas autoridades ambientais. Seus técnicos também não querem, pois, eles próprios, ser tomados por infratores da lei.

\section{Dissidências em torno da eutanásia}

Em paralelo à progressiva percepção do quadro de marginalidade institucional em que se encontrava inserida, a equipe do HUV passou a encenar outro peculiar processo de mudança interna, ligado ao estabelecimento de renovados parâmetros de elegibilidade da eutanásia como alternativa de intervenção aos casos ali tratados. (Aliás, o conceito de eutanásia aqui empregado é aquele previsto na Resolução CFMV 1000/2012: “a indução da cessação da vida animal, por meio de método tecnicamente aceitável e cientificamente comprovado, observando os princípios éticos").

A partir de determinado momento, tornaram-se mais constantes e incisivas as recomendações de eutanásia aos animais atendidos no HUV. Justificavam-se tais recomendações, frequentemente, por meio do argumento de que as injúrias sofridas por determinados animais seriam incompatíveis com a vida, ou com a qualidade de vida. Porém, em algumas dessas situações, embora as injúrias representassem um estado de sofrimento visivelmente intenso aos animais, elas eram perfeitamente suscetíveis de tratamento e de restituição de níveis apropriados de bem-estar. A mais arguta percepção acerca das especificidades desse processo consta do relato de X., médica veterinária atuante no HUV desde sua fundação

Até hoje, todos os pacientes eletrocutados (...) apresentaram lesões chocantes, muito feias de se ver, e muitas vezes já estão com o mau cheiro da necrose, que é causada pelo acidente de eletrocussão. Então, nós vemos o sofrimento do animal, e isso causa uma rejeição do nosso olhar. E a primeira atitude da pessoa que olha essa situação é: 'vamos acabar com o sofrimento por meio da eutanásia'. Mas eu fico pensando: esse animal não chegou até nós à toa. Ele chegou porque alguém soube que nós atuamos com animais silvestres, e que somos um hospital. Então, como será que as pessoas enxergam o fato de existir um hospital de silvestres? Elas muitas vezes pensam: 'até tal dia, nós não tínhamos para onde levar um animal desse, e hoje nós temos'. Então, nesse primeiro momento, é difícil, pois um colega chocado te indica: 'eu acho que esse é um caso de eutanásia'. E todos acabam tomados pelo sentimento de choque, por verem um animal sofrendo tanto. Mas o nosso papel como médicos veterinários, dentro de um hospital, é oferecer ao paciente aquilo que ele está precisando. (...) [E] qualidade de vida é um conceito subjetivo. Até uma pessoa que sofre um acidente tem uma qualidade de vida reduzida de imediato, perante alguém que está são. Porém, ela pode recobrar, sim, dentro de limitações, uma elevada qualidade de vida. São casos em que se perde a qualidade de vida, mas, dentro daquele contexto, é possível tratar da melhor forma. (...) [Além disso], dentro do ambiente hospitalar, nós temos todo esse aparato que permite que possamos lutar pela vida do animal até onde não tivermos mais o que fazer. Só que também a decisão de quando não temos mais o que fazer, ela deve ser tomada com muita responsabilidade.

Nota-se, na fala de X., a percepção de que o termo hospital, enquanto categoria institucional, porta significados específicos, ligados tanto ao compromisso primordial do veterinário com a restituição da saúde a seus respectivos pacientes, quanto à capacidade técnica de ofertar serviços complexos, inclusive situados na fronteira do conhecimento científico estabelecido. Assim, a banalização do recurso à eutanásia equivaleria à negação dessas especificidades, a uma empobrecedora equiparação dessa categoria àquelas já previstas nos regulamentos do setor de meio ambiente. 
Conforme ressaltado por X., a própria regulamentação exarada pela entidade de fiscalização do exercício profissional da Medicina Veterinária não se compatibilizaria com o entendimento mais favorável à eutanásia, que vinha se desenhando no HUV. Referindo-se ao artigo 3ำ, inciso I, da Resolução CFMV 1000/2012, X. pontuou que o recurso à eutanásia apenas deveria ser aventado na seguinte situação:

(...) quando o bem-estar do animal estiver comprometido irreversivelmente, não sendo possível amenizar a dor ou resolver seu caso por técnicas ou medicamentos. Então, esse tópico deve nortear também as nossas decisões. Será que não temos mais nada que possamos fazer? Será que é irreversível? Temos que tomar a decisão da irreversibilidade baseados em fatos consistentes. E que fatos são esses? Exames complementares, exames físicos, análise de toda a equipe, que construirá um laudo, determinando essa decisão.

Assim, as dissidências internas relativas a uma racionalidade pró-eutanásia foram confrontadas com a necessidade de que as decisões se pautassem por critérios estritamente técnicos, e não passionais. A formalização desta postura foi viabilizada pela instituição de uma nova tipologia documental, o 'Laudo decisório sobre o paciente crítico ou terminal'. Este laudo decorre de meticulosa investigação, por meio de exames devidamente documentados, e é redigido coletivamente, sendo também subscrito por todos os membros da equipe envolvida com cada respectivo caso. Desse modo, a decisão é conjunta, como também a correlata responsabilidade profissional, e, por isso, deve se respaldar em justificativa tecnicamente fundamentada.

\section{Ligando os pontos: o que sugere a postura pró-eutanásia?}

Ultrapassadas, no plano institucional, as disputas em torno dos parâmetros de elegibilidade da eutanásia, subsiste, ainda, no plano teórico, a oportunidade de reflexão acerca das razões pelas quais, em certo momento, o procedimento se afigurou como alternativa de diferenciada valorização por parcela da equipe do HUV. Como antes mencionado, a empatia despertada pelo quadro de sofrimento de alguns animais conduzidos ao hospital representa relevante fator de mitigação da certeza de que a manutenção da vida deveria ser o valor precípuo a ser perseguido pelo veterinário. Mas, para além desta evidente motivação, também se pode notar, nas entrelinhas do argumento relativo à incompatibilidade de certas injúrias com a qualidade de vida, que o que se pretende de fato indicar é a improbabilidade de que determinados animais, ainda que tenham restituídos níveis satisfatórios de bem-estar, retornem à vida livre (ao ambiente natural ou a ambientes seminaturais protegidos).

As dissidências em torno da eutanásia permitem reconhecer que a visão que se instalava no HUV era a imagem dos pacientes como fauna, como bem ambiental, cujo valor estaria limitado à possibilidade de reintegração à vida livre. Nesta visão, apenas seria oportuno investir no tratamento de animais que detivessem reais chances de retorno à natureza, abreviando-se o sofrimento daqueles severamente machucados. Insinuava-se, pois, o risco de renúncia da lógica específica norteadora da ação hospitalar, em favor da adesão à lógica própria dos órgãos ambientais. Vistos mais como fauna que como pacientes, os animais conduzidos ao HUV estariam submetidos a critérios de valoração estranhos ao supremo valor de manutenção da vida, em flagrante desacordo com a própria orientação do CFMV. 
Se isto, em algum momento, se tornou evidente para os próprios sujeitos envolvidos, jamais foi explicitado pelos interlocutores no curso desta pesquisa. A ação de X., entretanto, ao estipular a nova tipologia de laudo no HUV, além de chamar à ordem a questão da responsabilidade profissional, revitalizou as linhas de distinção existentes entre órgãos ambientais e órgãos hospitalares. A irredutibilidade da figura do paciente ao conceito de mero bem ambiental, aliás, é reconhecida pela própria X., quando remonta aos primórdios da fundação do HUV, capitaneada por um conjunto de pesquisadores com tradição na área de reprodução animal. Para a interlocutora, limitações substanciais à expressão do modo de vida natural de um animal, como amputações de membros, e a consequente impossibilidade de sua reintegração à vida livre não podem ser referidas como argumentos válidos para arguir a incompatibilidade com a vida, pois:

Este animal pode não exercer sua biologia de locomoção, subir em uma árvore novamente, mas será que para um programa de reprodução, para a conservação daquela espécie, será que ele não é importante?.

A própria estruturação de um hospital - seus recursos, equipamentos e quadro funcional - possibilita estratégias de atuação especializadas, que criam verdadeira obrigação ética de intervir, de prover as ações tecnicamente possíveis e necessárias à manutenção da vida de seus pacientes e reabilitação de níveis adequados de bem-estar. Permitem, desse modo, ultrapassar a estrita tarefa de seleção de animais aptos ou inaptos à futura reintrodução. Permitem que a instituição realize seu propósito de posicionar a continuidade de cada vida individual - e não da abstrata fauna - como valor central de seus esforços.

Enfim, parece estar, na raiz dessa celeuma, a negação da possibilidade de o HUV se afirmar como categoria institucional diferenciada e a imposição de que ele se enquadrasse em alguma das categorias existentes de manejo de fauna silvestre em cativeiro. A negativa de reconhecimento da categoria hospital, pois, deve ter fornecido condições de reflexão propícias para que alguns dos técnicos do HUV passassem a crer que precisavam aderir à lógica de ação dos órgãos ambientais e das categorias de criadouros por eles reconhecidas, em detrimento da lógica hospitalar preexistente, que demarcaria uma diferenciação supostamente ilegítima.

\section{Utopias semidomesticadas}

Com base no exposto, é possível destacar dois pontos que convergem para a ideia de domesticação das utopias conservacionistas fundantes da iniciativa do HUV. Um ponto é a postura inquisitiva adotada pela equipe do HUV perante as pessoas que conduzem animais silvestres até o local, denotando certa naturalização do discurso oficial, que, em regra, criminaliza o intercurso humano com a fauna silvestre. 0 outro, foi a proliferação de recomendações favoráveis à eutanásia de animais silvestres insuscetíveis de retorno à vida livre, em determinado momento da história do HUV. Ambos ilustram um processo de parcial abdicação de um determinado conjunto de valores e compromissos e adesão aos pressupostos e modos de valoração próprios dos órgãos ambientais, cuja lógica de ação se pauta pelo modelo burocrático (ou legalista). Tal fenômeno de domesticação de utopias, em grosseira analogia ao processo de seleção artificial de variedades de plantas e animais, também corresponde a uma modalidade de adaptação socialmente dirigida. 
No primeiro caso, a distância criada entre o HUV e os portadores de animais não traz nenhum ganho para o combate à exploração predatória da fauna, uma vez que os citados condutores claramente não atuam como traficantes de animais, sendo meros elos humanos das relações da sociobiodiversidade amazônica. Não surtindo efeito sobre o tráfico de fauna, a cisão imposta ainda cerceia as possibilidades de articulação social do HUV, excluindo a entidade de importantes elos de interação no circuito de tutela da fauna silvestre amazônica. Ou seja, o HUV perde significativa parcela de sua potencial relevância conservacionista, pois abdica de participar de importantes processos de intercurso homem $\mathrm{x}$ fauna, mas permanece submisso à lei.

No segundo caso, mesmo quando os animais chegam ao HUV, não têm garantia de que a simples manutenção de suas vidas e a restituição de seu bem-estar serão os valores preponderantes a nortear as decisões dos veterinários. Aqui, novamente, a instituição perde relevância conservacionista, pois o atendimento dos pacientes tende a ser influenciado pela avaliação da possibilidade de seu futuro regresso ao ambiente natural, independentemente da consideração de outros valores que se possam atribuir ao animal, para além de seu valor como vida selvagem. Seu valor genético, seu valor reprodutivo, seu valor como criatura dotada de vida são, pois, mitigados em face da noção de fauna silvestre como elemento externo ao mundo humano.

Embora seja contraditório, quanto mais o HUV persegue a necessária conformidade legal, mais parece ter que negociar e relativizar seus valores fundantes, domesticando e adaptando suas utopias conservacionistas à lógica de ação burocrática do sistema público de gestão ambiental. Garante a legalidade de seus atos, mas à custa da própria efetividade de suas ações sobre a vida de cada paciente e, de modo mais amplo, sobre o conjunto da fauna silvestre local.

O HUV e seus técnicos - alguns mais conscientes disso que outros - se encontram em situação de liminaridade, divididos entre dois universos de valores. Dois universos que não precisariam estar cindidos, embora, circunstancialmente, no caso brasileiro, estejam. É, enfim, como forma de ponte entre a atual configuração do sistema público de gestão ambiental do país e a especificidade aqui atribuída ao HUV que se argumenta, a seguir, sobre a pertinência - verdadeira necessidade - de que os hospitais de animais silvestres sejam reconhecidos como categoria própria de estabelecimento de manejo da fauna silvestre em cativeiro.

\section{Hospital: especificidades}

Defende-se, portanto, com base no caso relatado, que a noção de 'hospital de animais silvestres' é portadora de especificidades que justificam sua definição como categoria diferenciada de estabelecimento de manejo da fauna silvestre em cativeiro. A especificidade básica reside no fato de que o valor máximo em torno do qual se estrutura o funcionamento da instituição é a vida. Busca-se manter o paciente vivo e restituir seu bem-estar até níveis satisfatórios. Quando, porém, questões paralelas, como a busca pela responsabilização de supostos infratores, concorrem pela prioridade das atenções, a efetividade das intervenções médico-veterinárias resta prejudicada, como as próprias experiências vividas no HUV exemplificam. 
Em segundo lugar, um hospital se diferencia das categorias já existentes de estabelecimentos de manejo da fauna por organizar sua infraestrutura e seus recursos humanos e materiais em conformidade ao precípuo objetivo acima indicado. Encontra-se, portanto, capacitado a executar intervenções complexas que, sob a ótica do objetivo de reintrodução dos animais na natureza, poderiam ser consideradas não convenientes ou até supérfluas, pois não necessariamente conducentes a graus de reabilitação adequados à soltura dos respectivos pacientes no ambiente natural.

Em terceiro lugar, decorrendo dos esforços ligados à busca da reabilitação da saúde e do bem-estar dos animais, o hospital se torna - mais que as categorias já estabelecidas - espaço de inovação técnica e produção de conhecimentos. Não servindo como depósito de animais apreendidos pelos órgãos ambientais, um hospital recebe somente os casos que de fato necessitam de intervenção médico-veterinária especializada. Enquanto se concentram em uma quantidade menor de casos, seus técnicos se debruçam de modo mais detido sobre a situação de cada paciente, tendo, inclusive, que propor métodos terapêuticos inovadores para lidar com quadros patológicos para os quais a literatura especializada oferece pouco suporte. (É de se cogitar, aliás, que a escassez de bibliografia sobre a terapêutica aplicável a animais silvestres decorra da vigente estratégia de gestão ambiental da fauna que, priorizando as ações de triagem e soltura de animais, desvaloriza e dificulta a ação hospitalar). Segundo a interlocutora X.:

Já que os livros não tinham 'como tratar uma preguiça eletrocutada', hoje nós podemos escrever esse livro com a nossa vida. Eu falo para os residentes: se, naquele momento, nós tivéssemos decidido fazer a eutanásia, quanto conhecimento teria ido junto com a embalagem com a qual o animal seria descartado? Quanto conhecimento teria sido enterrado junto com aquela decisão da eutanásia? E um conhecimento, claro, muito responsável.

Em quarto lugar, destaca-se que a dispendiosa estruturação de um hospital veterinário ocorre, geralmente, associada a alguma instituição de ensino superior que oferta o curso de bacharelado em medicina veterinária. Desse modo, reforça-se a visão do hospital como espaço de produção do conhecimento (pois ligado a uma instituição que, por força da Lei 9.394 de 1996, se pauta pelo tripé ensino-pesquisaextensão) e se desvela seu papel formativo. Trata-se, afinal, de espaço onde ocorre a preparação de estudantes para futura atuação como veterinários, como também a especialização de profissionais já diplomados em programas de residência médico-veterinária. Espaço, pois, onde se devem formar valores compatíveis com a ética médica e com a priorização da vida dos pacientes.

Transformados os hospitais em centros de triagem ou reabilitação, instituições como o HUV deixariam de figurar como privilegiado espaço de educação médico-veterinária. Sobrecarregados pelo intenso influxo de animais oriundos de apreensões, adotariam como valor norteador de sua atuação não a vida, mas a possibilidade de futura devolução dos animais à natureza. Descartando casos graves ou de incerta possibilidade de reabilitação do animal para soltura, seus técnicos não encontrariam condições para desenvolver inovação técnica nem produzir conhecimentos correlatos a situações demandantes de intervenção complexa. O veterinário formado neste tipo de ambiente seria, além de uma pessoa alienada em relação às discussões sobre sociobiodiversidade, profissional com limitada habilidade para lidar de modo efetivo com o dever de prestar assistência aos animais silvestres. 
Abdicar do reconhecimento como hospital e buscar enquadramento como centro de triagem ou reabilitação significaria, enfim, negar as especificidades do HUV e instituições congêneres, esvaziar suas utopias fundantes. Ressoando o modelo burocrático de gestão pública, tal movimento representaria a conquista da plena conformidade legal, porém à custa da efetividade das ações no campo do conservacionismo e da proteção dos animais.

\section{Comentário antropológico}

Apresentados os argumentos em prol do reconhecimento da especificidade e da relevância ambiental da categoria 'hospital de animais silvestres', resta, ainda, a oportunidade de refletir sobre os motivos por que este reconhecimento até então não logrou êxito. Em primeiro lugar, é óbvio que isto não pôde ocorrer devido à redação da Instrução Normativa no 7 de 2015 do Ibama, que impõe a exclusividade das categorias ali listadas, dentre as quais não consta a de hospital.

E embora esteja correta a citada explicação, o caráter burocrático e legalista da máquina estatal brasileira - e, consequentemente, dos órgãos ambientais - talvez não explique, por si, a negativa em relação à categoria de hospital. Certamente há um pendor pela estabilidade jurídica, dotando as instituições de certo imobilismo de práticas e categorizações. Porém, no que concerne à tutela da fauna, cogita-se estar em jogo não apenas um quadro classificatório de instituições, mas uma cosmologia de relações ideais entre sociedade e natureza, em face dos tabus que lhe fazem oposição.

Considere-se o seguinte: um hospital, tal qual o próprio HUV, tem por missão precípua a manutenção da vida de seus pacientes e a restituição de adequados níveis de bem-estar. Complementarmente, buscamse ofertar tratamentos que permitam a reintrodução dos animais ali atendidos na natureza. Em alguns casos, porém, o retorno ao ambiente natural é inviável e deve-se buscar outra destinação legal para o paciente após a alta médica. Nestes casos, há a recuperação, mas não a plena reabilitação do paciente às suas condições naturais de sobrevivência em vida livre.

A cosmologia ocidental/urbana inspiradora do ordenamento jurídico brasileiro concebe, no entanto, os animais silvestres, como elementos de uma natureza distante, exótica e inviolável, que deve ser mantida sob proteção contra o intercurso com o mundo humano. Esta visão está especialmente implícita na Lei 9.605 de 1998 e no Decreto 6.514 de 2008 e foi anteriormente discutida por Ruas et al. (2017).

E quando o HUV, movido por utopias próprias, se dispõe a recuperar animais insuscetíveis de plena reabilitação, produz objetos que representam a negação da cosmologia dominante: animais silvestres incapazes de retornar a seu próprio mundo e condenados a se incorporarem ao mundo humano, aos cuidados de tutores. As ações de um hospital de animais silvestres estariam, assim, voltadas à subversão de uma ordem vista como natural, segundo a qual os animais silvestres, por definição, seriam aqueles vivendo em liberdade, legítimos receptores da proteção governamental.

Os animais recuperados e parcialmente reabilitados, ao contrário, constituiriam uma subclasse degenerada da fauna silvestre, objetos profanos a macular a ordem natural do mundo. Seriam objetos tão 
nefastos e deslocados, que sequer mencionados pela legislação ambiental. É como se, maculadas a sacralidade e a intangibilidade da vida selvagem, o animal silvestre perdesse seu valor enquanto tal.

A ideia ora proposta não é nova, mas simples desenvolvimento a partir do conceito de híbrido, tal qual formulado por Latour (1994). Segundo o autor, o ideário da modernidade (período histórico iniciado no século $\mathrm{XVI}$ ) seria caracterizado pela racionalidade e pela completa cisão entre dois polos: natureza e sociedade (ou cultura). Nesta visão de mundo, tudo o que não pudesse ser classificado como objeto nem como sujeito estaria perdido entre os dois polos e não mereceria reconhecimento enquanto ser. Argumenta Latour, porém, que tal visão produziu equívocos em série, impondo a necessidade de renúncia às tentativas de forçada redução dos híbridos às condições de ser natural ou ser social/cultural. Seria preciso compreendêlos a partir de seu caráter complexo, como seminatural-semi-humano. Tomando o exemplo do buraco da camada de ozônio, Latour afirma que sua correta compreensão apenas poderia ocorrer se conjugados os fatores naturais e socioculturais intervenientes. Analogamente, no caso ora abordado, os pacientes insuscetíveis de plena reabilitação que o HUV se propõe a recuperar também podem ser entendidos como formas híbridas, destinadas a existir entre o mundo natural e o humano, e tão insondáveis à abordagem reducionista ainda predominante, que consideradas indignas profanações.

Portanto, a oposição ao reconhecimento da categoria hospital decorreria, sim, da tendência imobilista ligada ao modelo burocrático da máquina estatal, mas igualmente do projeto de deslegitimação desta tipologia institucional, produtora de objetos profanos e degenerados. Projeto de descaracterização das utopias dissonantes e de sua contaminação pelos valores da agenda ambiental dominante.

\section{CONCLUSÕES}

A imperatividade da lei e o estado de pacificação social ao qual sua observância, em tese, conduz não deveriam servir de argumentos para a recusa da discussão sobre a pertinência ou impertinência de um ou outro dispositivo legal em face das mudanças sociais e da erupção de emergentes questões e problemáticas da vida contemporânea. Nunca é demais lembrar, por sinal, que a fiel obediência à lei foi inúmeras vezes mobilizada como argumento legitimador até mesmo de condutas tão atrozes como aquelas perpetradas, por exemplo, na Alemanha nazista.

O caso relatado, pois, abordando uma situação de incompatibilidade entre a ideia de hospital e as categorias juridicamente previstas de estabelecimentos de manejo da fauna silvestre em cativeiro, demonstra como a posição de estrita legalidade pode significar não somente a negação do mundo socialmente produzido, mas a inviabilização dos objetivos fundantes das próprias leis.

Não se nega que as leis ambientais brasileiras tenham sido criadas com o intuito de proteger o meio ambiente e todos os seus componentes, inclusive os seres vivos e particularmente a fauna. Porém, como o caso em questão ilustra, essas mesmas leis servem como fundamento para dificultar o reconhecimento de novas iniciativas que, por suas intrínsecas especificidades, poderiam dotar de maior efetividade a busca pela conservação ambiental. 
A proposta presentemente formulada não corresponde, portanto, a um simples capricho referente à nomenclatura 'hospital de animais silvestres'. Trata-se de uma verdadeira necessidade de diferenciação, capaz de refletir a especificidade do papel socioambiental do HUV e instituições congêneres, de sua lógica de intervenção e de seus valores fundantes. Trata-se, enfim, de uma categoria irredutível às categorias previstas na legislação e cujo não reconhecimento ilustra a indisposição do aparelho estatal em prover a participação popular na gestão do meio ambiente.

\section{REFERÊNCIAS}

ABRUCIO, F. L.. O impacto do modelo gerencial na Administração Pública: um breve estudo sobre a experiência internacional recente. Cadernos ENAP, n.10, 1997.

ADAMS, C.. As populações caiçaras e o mito do bom selvagem: a necessidade de uma nova abordagem interdisciplinar. Revista de Antropologia, v.43, p.145-182, 2000.

ARRUDA, R.. Populações tradicionais e a proteção dos recursos naturais em unidades de conservação. Ambiente e sociedade, n.5, p.79-92, 1999.

BAÍA JÚNIOR, P. C.; GUIMARÃES, D. A.; PENDU, Y.. Nonlegalized commerce in game meat in the Brazilian Amazon: a case study. Revista de Biologia Tropical, v.58, n.3, p.10791088, 2010.

BARROS, F. B.; AZEVEDO, P. A.. Common opossum (Didelphis marsupialis Linnaeus, 1758): food and medicine for people in the Amazon. Journal of Ethnobiology and Ethnomedicine, n.10, p.65, 2014.

BAUMAN, Z.; MAY, T.. Laços: para falar em 'nós'. In: BAUMAN, Z.; MAY, T.. Aprendendo a pensar com a Sociologia. Rio de Janeiro: Zahar, 2010. p.75-94.

BERGER, P. L.; LUCKMANN, T.. The social construction of reality: a treatise in the Sociology of knowledge. New York: Penguin Books, 1966.

BRESSER-PEREIRA, L. C.. Da administração pública burocrática à gerencial. Revista do Serviço Público, v.47, n.1, p.7-40, 1996.

CASTRO, C.; O'DONNELL, J.. O tipo ideal do 'homem cordial' brasileiro. In: CASTRO, C.; O'DONNELL, J.. Introdução às Ciências Sociais. Rio de Janeiro: Fundação Getúlio Vargas, 2015. p. 55-66.

CFMV. Conselho Federal de Medicina Veterinária. Resolução n.829: Disciplina o atendimento médico veterinário a animais silvestres/selvagens e dá outras providências. Brasília: Diário Oficial da União, 2006.

CFMV. Conselho Federal de Medicina Veterinária. Resolução n.1000: Dispõe sobre procedimentos e métodos de eutanásia em animais e dá outras providências. Brasília: Diário Oficial da União, 2012.

CONAMA. Conselho Nacional de Meio Ambiente. Resolução n.489: Define as categorias de atividades ou empreendimentos e estabelece critérios gerais para a autorização de uso e manejo, em cativeiro, da fauna silvestre e da fauna exótica. Brasília: Diário Oficial da União, 2018.

COSTA, F. L.. Brasil: 200 anos de Estado; 200 anos de administração pública; 200 anos de reformas. Revista de Administração Pública, v.42, n.5, p.829-874, 2008.

DIEGUES, A. C. S.. O mito moderno da natureza intocada. 3 ed. São Paulo: Hucitec/NUPAUB/USP, 2000.

DURHAM, E. R.. A autonomia universitária - extensão e limites. In: STEINER J. E.; MALNIC, G.. Ensino Superior: conceito e dinâmica. São Paulo: EDUSP, 2006. p.79-124.

FÜRSTENAU-TOGASHI, H.; SOUZA-HACON, V.. A evolução do debate socioambiental no Brasil: Legislação, etnoconservação e racionalidade ambiental. Economía, sociedad y territorio, v.12, n.39, p.403-424, 2012.

HOLANDA, S. B.. Raízes do Brasil. Rio de Janeiro: José Olympio, 1936.

IBAMA. Instituto Brasileiro do Meio Ambiente e dos Recursos Naturais Renováveis. Instrução Normativa n.07: Institui e normatiza as categorias de uso e manejo da fauna silvestre em cativeiro. Brasília: Diário Oficial da União, 2015.

JUSTEN FILHO, M.. Curso de Direito Administrativo. 12 ed. São Paulo: Revista dos Tribunais, 2016.

LATOUR, B.. Jamais fomos modernos: ensaio de Antropologia simétrica. Rio de Janeiro: 34, 1994.

LICARIÃO, M. R.; BEZERRA, D. M. M.; ALVES, R. R. N.. Wild birds as pets in Campina Grande, Paraíba State, Brazil: an ethnozoological approach. Anais da Academia Brasileira de Ciências, v.85, n.1, p.201-213, 2013.

MEDEIROS, P. H. R.. Do modelo racional-legal ao paradigma pós-burocrático: reflexões sobre a burocracia. Revista Organizações \& Sociedade, v.13, n.37, p.143-160, 2006.

MORSELLO, C.; YAGÜE, B.; BELTRESCHI, L.; VLIET, N.; ADAMS, C.; SCHOR, T.; QUICENO-MESA, M. P.; CRUZ, D.. Cultural attitudes are stronger predictors of bushmeat consumption and preference than economic factors among urban Amazonians from Brazil and Colombia. Ecology and Society, v.20, n.4, p.21-39, 2015.

PARRY, L.; BARLOW, J.; PEREIRA, H.. Wildlife harvest and consumption in Amazonia's urbanized wilderness.

Conservation Letters, v.7, n.6, p.565-574, 2014. 
PEREIRA, G. A.; BRITO, M. T.. Diversidade de aves silvestres brasileiras comercializadas nas feiras livres da Região Metropolitana do Recife, Pernambuco. Atualidades Ornitológicas, v.126, n.14, 2005.

REBÊLO, G.; PEZZUTI, J.. Percepções sobre o consume de quelônios na Amazônia. Sustentabilidade e alternativas ao manejo atual. Ambiente e Sociedade, v.3, n.6/7, 2000.

RIBEIRO, A. S. S.; PALHA, M. D. C.; TOURINHO, M. M.; WHITEMAN, C. W.; SILVA, A. S. L.. Utilização dos recursos naturais por comunidades humanas do Parque Ecoturístico do Guamá, Belém, Pará. Acta amazônica, v.37, n.2, p.235240, 2007

RUAS, R. M. S.; FURTADO, D. C.; GUERRA, G. A. D.; LOPES, C. T. A.; DOMINGUES, S. F. S.. Caça, captura e uso da fauna silvestre no Brasil como crimes ambientais e tabu científico: reflexão sobre categorias teóricas. Holos, v.33, n.5, p.37-54, 2017.

SÁEZ, O. C.. Esse obscuro objeto da pesquisa: um manual de método, técnicas e teses em Antropologia. Florianópolis, 2013.
SARAI, L.. Repensando o conceito de administração pública na busca da máxima efetividade de seus princípios constitucionais. Jus Navigandi, v.16, 2011.

SCHIER, P. R.. Ensaio sobre a supremacia do interesse público sobre o privado e o regime jurídico dos direitos fundamentais. Revista de Direito Administrativo e Constitucional, v.4, n.17, 2004.

SILVA, A. L.. Animais medicinais: conhecimento e uso entre as populações ribeirinhas do rio Negro, Amazonas, Brasil. Boletim do Museu Paraense Emílio Goeldi, v.3, n.3, p.343357, 2008.

TÖNNIES, F.. Comunidade e sociedade como entidades típico-ideais. In: FERNANDES, F.. Comunidade e sociedade. São Paulo: Companhia Nacional, 1973. p.96-116.

VLIET, N.; QUICENO, M. P.; CRUZ, D.; AQUINO, L. J. N.; YAGÜE, B.; SCHOR, T.; HERNANDEZ, S.; NASI, R.. Bushmeat networks link the forest to urban areas in the trifrontier region between Brazil, Colombia and Peru. Ecology and Society, v.20, n.3, p.21-41, 2015.

A CBPC - Companhia Brasileira de Produção Científica (CNPJ: 11.221.422/0001-03) detém os direitos materiais desta publicação. Os direitos referem-se à publicação do trabalho em qualquer parte do mundo, incluindo os direitos às renovações, expansões e disseminações da contribuição, bem como outros direitos subsidiários. Todos os trabalhos publicados eletronicamente poderão posteriormente ser publicados em coletâneas impressas sob coordenação da Sustenere Publishing, da Companhia Brasileira de Produção Científica e seus parceiros autorizados. Os (as) autores (as) preservam os direitos autorais, mas não têm permissão para a publicação da contribuição em outro meio, impresso ou digital, em português ou em tradução. 